Rita Biconne 26

\title{
11 Measures of Adaptation and Community-based Water Management in Mékhé, Senegal
}

\begin{abstract}
Water and ecological stressors that have decreased resource availability result in increased social and territorial disparities from the viewpoint of quantity and quality. The challenge increases in contexts characterized by critical environmental and climatic conditions, such as those found in many Sub-Saharan African countries, where local priorities are heavily influenced by survival needs. The ability to cope with a situation of water scarcity is contingent on the interaction among environment, economy and society. According to Ohlsson, adapting to natural resource scarcities involves the mobilization of an increased level of social resources. These social resources can be identified with the "adaptive capacity" of a given society. To make the relevant adjustments needed to cope with increased resource scarcity, a social entity could find the social tools enabling it to deal with the consequences of the water scarcity. In this framework, local communities and associations play a central role relative to institutional failures in an articulated relationship between responsibility and interest. The experience of water access and management for irrigation led by an inter-village peasant organization in Mékhé, Senegal, will be analysed to show a feasible way to implement new opportunities facing climatic challenges.
\end{abstract}

Keywords: Adaptive capabilities, Water scarcity, Climate change

\subsection{Introduction}

Water is the fundamental link between the climate system, human society and the environment, and it is the primary medium through which Climate Change (CC) impacts the livelihood and wellbeing of societies.

According to the Fourth Assessment Report of the Intergovernmental Panel on Climate Change (IPCC), rainfall is generally expected to become more variable, floods are expected to become more common, droughts are expected to become more intense and last longer, and sea-levels are expected to rise. "The effect of all these impacts is reduced availability of water (surface and groundwater) and reduced security of supply. This phenomenon is spatially variable, particularly against the background of

26 Department of Architecture, University of Florence, Italy, rita.biconne@gmail.com.

This chapter resume part of the $\mathrm{PhD}$ thesis "Access to water. Actors and planning in the territories of Senegal” discussed in 2013 at the University of Florence. The author thanks "Fratelli dell'Uomo" NGO, Union of peasants of Mékhé and KAYER - Kayor Energie Rurale for the support and information provided in Mékhé. 
high evaporation rates and low rainfall under natural conditions as well as increased demands for water to support development, among others. This effect also depends on the water supply system and the ability of politicians, planners and managers to respond also to population growth and changes in demands, technology, economic, social and legislative conditions" (IPCC, TAR 2001).

The literature recognises the impact of climate-driven water shortages and emphasizes the vulnerable and poor communities due to their lack of resilience (Ziervogel et al. 2008; IPCC 2007). In particular, according to Eboh (2009), countries of sub-Saharan Africa are likely to suffer from these devastating impacts because of their geographical location, low incomes, low technological and institutional capacity to adapt to rapid changes in the environment, as well as their higher reliance on climate-sensitive renewable natural resources sectors such as water and agriculture.

This chapter will discuss some of these aspects, mainly focusing on water management connecting environmental challenges to the agricultural use of water. First, the paper proposes some concepts related to water scarcity, focusing on physical and climatic issues (as aridity, drought), as well as political and social features linked to the theory of "social scarcity" and adaptation processes. Secondly, through a case study, this essay will explore a possible path to cope with water scarcity, aiming to integrate the social, environmental, spatial, economic and political issues of water management.

The hypothesis we are going to present is the following: in the process of water management and its related responsibilities concerning monitoring, regulation and usage, especially under the condition of vulnerability resulting from CC, might give rise to ways of adaptation propelled by the skills of local actors to mobilise the available resources, both material and immaterial ones.

The selected case study takes place in the extended hinterland of the Senegalese capital city. It represents a very interesting context to study due to its location in the ever-growing urban corridor ${ }^{27}$ between Dakar and Touba, the two biggest cities in Senegal.

Relating to CC impacts, this interest is due to the very poor scientific data and awareness of what is going on in the hinterland and in particular in the new spatial configuration of territories touched by urban corridor development. This chapter aims to contribute to this topic, focusing on water scarcity and related adaptation measures at the community level.

27 "In sub-Saharan Africa, as well as in all regions where trade between cities and their hinterlands has accelerated, urban development corridors are now arising in the wake of rapid demographic expansion and urbanisation. An urban development corridor can arise where two or more large urban centres are located along a single connection trunk line (road, rail, sea or river) that is organised so as to attract flows of people, goods and services while large and regular trade flows pass through urban or rural transit points between the larger urban centres" (UN-Habitat 2010: 129). 
The selected context is characterized by a webbed and hierarchical structure of villages. Both the social and spatial implications stemming from the location and the distribution of water resources require accurate reflection.

The starting point of this discussion is recognizing that territory is not only deemed to be a physical support, but also influences the social organization and structure on the basis of history of settlement and on the ties that social groups have established with the territory itself, and with other social groups. Therefore, managing the territory and its related natural resources means not exclusively considering technical decisions as the rules to adopt. Advantages and utility are shaped by the array of rights and obligations of social actors in this resource-space where different roles, responsibilities and forms of power are taking new shapes to face current challenges.

\subsection{Adapting to Water Scarcity}

Climate Change is aggravating the challenges of water resources access and management in Sub-Saharan Africa, with serious implications on socio-economic development. IPCC (2001) noted that these challenges include population pressure, problems associated with land use and possible ecological consequences of land-use change on the hydrological cycle. Climate change - especially changes in climate variability through droughts and flooding - will make addressing these problems more complex. The current condition of water access worsened because of the many components exerting an impact on water scarcity. The Human Development Report Beyond scarcity: Power, poverty and the global crisis (UNDP 2006) considered water scarcity from two points of view: a) as a crisis arising from a lack of services that provide safe water, and b) as a crisis due by scarce water resources. Above all, it underlined that water scarcity in the World is not related to the physical availability, but to unbalanced power relations, poverty and related inequalities.

Water scarcity is a very critical phenomenon in arid and semi-arid regions in different parts of the World (Figure 11.1). Specifically, the Sub-Saharan African countries suffer from a particular type of water scarcity, an important issue that requires precise consideration.

Despite some common errors of understanding, scarcity is not a synonym of aridity; the two terms are not equivalent concepts. Aridity expresses a condition that characterizes specific ecosystems and natural environments; scarcity, which is often mistakenly associated with data exclusively related to climatic, physical and hydrogeological features, represents a problem of various kinds. In fact, water scarcity can have manifold causes, both natural and man-made, and corresponds to several regimes.

As underlined by Pereira (2005), the main natural causes for scarcity are aridity and droughts, and he offers the following definition of the two concepts. 


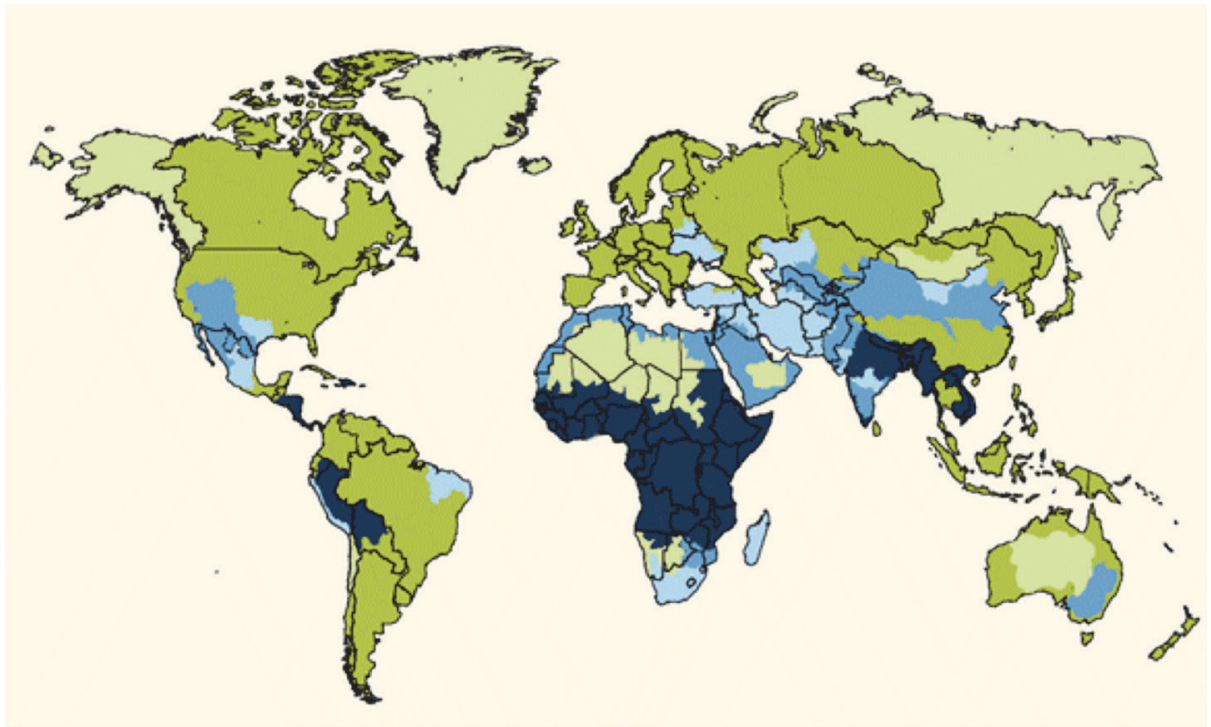

Figure 11.1: Physical water scarcity (light blue), economic water scarcity (dark blue), no water scarcity (green). Source: UN-Water, 2012.

"Aridity is a nature produced permanent imbalance in the water availability consisting in low average annual precipitation, with high spatial and temporal variability, resulting in overall low moisture and low carrying capacity of the ecosystems. [...] Drought is a nature produced but temporary imbalance of water availability, consisting of a persistent lower-than-average precipitation, of uncertain frequency, duration and severity, the occurrence of which is difficult to predict, resulting in diminished water resources availability and carrying capacity of the ecosystems" (Pereira et al. 2005: 2).

More recently, man-driven processes, such as man-induced desertification and water shortages ${ }^{28}$, are aggravating natural scarcity, while population growth and the demand for water faces an increased competition among water user sectors and regions.

According to Pereira (2005), the fact is that negative socio-economic conditions in the vulnerable areas are often related to poor land resources, mainly soil and water,

28 "Desertification is a man-induced permanent imbalance in the availability of water that occurs in arid, semiarid and sub-humid climates, which is combined with damaged soil, inappropriate land use, mining of groundwater, increased flash flooding, loss of riparian ecosystems and a deterioration of the carrying capacity of the ecosystems. [...] Water shortage is also man-induced but temporary water imbalance including groundwater over exploitation, reduced reservoir capacities, disturbed and reduced land use, and consequent altered carrying capacity of the ecosystems" (Pereira et al. 2005: 4). 
inadequacy of ecosystems to support development, low response capacity to climate forcing, and non-existence of alternative activities to agriculture and forestry. Thus, climate conditions may exacerbate the vulnerability on water scarcity, affecting the socio-economic dimension, in addition to the environmental one.

Moreover, a region is in a state of high water-related criticality (susceptibility of a region or its population to crises) if water scarcity coincides with a low problemsolving capacity of the population (WBGU 1998).

In this sense, the research carried out by Ohlsson is a crucial turning point for the scientific literature on water scarcity. He introduces a level of scarcity - different from unchangeable data linked to environmental conditions - defined as "social scarcity", which is related to the lack of institutional and economic tools.

As a historical factor subject to constant change, according to Ohlsson, society (even if subjected to multiple political and cultural limits and constraints) can mobilize developing adaptive capacity allowing it to cope with the physical scarcity of resources. Indeed, in addition to the so called 'first-order resource', (i.e. a natural resource which is relevant to a population over time, and is becoming either more scarce or abundant), a 'second-order resource' has been identified as "the set of potential 'adaptive behaviours' stemming from the broader social context that can be used by decision-making elites, either legitimately or illegitimately. 'Adaptive behaviour' is an explicit response to the changing level of water scarcity which can assume a number of forms, such as voluntary rationing schemes, changes in cropping cycles, rainwater harvesting, groundwater mining, formal policies etc.” (Ohlsson and Turton 1999: 3).

Framing this theory, Ohlsson was the first to develop the interrelationship between water scarcity and adaptive capacity. By shifting the focus from the 'first-' to the 'second-order resource', an improved understanding of why and how certain societies cope with resource scarcity can be achieved.

Based on the concept of adaptive capacity, the notion of adaptive management has also been advocated by other scholars as the paradigm within which communities, planners and managers should operate, since resource management systems need to be able to adjust to sudden changes in the system (Jeffrey and Gearey 2006).

This requires a paradigm shift, where water management is flexible enough to adjust to changing socio-economic and environmental conditions. Therefore, it is necessary to take into account the environmental, technological, economic, political and cultural features of water systems (Biconne 2013a). Through the case study, the next section of the chapter will show the complementarity of these components to face water scarcity at the community level.

Indeed this paper aims to highlight that overcoming "social scarcity" can represent a necessary step in order to face the impacts of CC and also to turn this challenge into opportunity not to be missed. 


\subsubsection{Understanding Adaptation at Community Level}

According to the Intergovernmental Panel on Climate Change, adaptation to climate changes and variability requires the system adaptation to downsize the impact of climate changes, in order to exploit new opportunities and to cope with the consequences (IPCC 2001). In this sense, adaptation involves the action that people take as a response to current or foreseen climate changes to reduce adverse impacts or exploit the opportunities offered by climate changes. In terms of CC, this last part of the definition is meaningful since climate changes also offer certain opportunities and advantages for communities to reduce their vulnerability or increase their resilience to climate shocks (Parry et al. 2005; Dinar et al. 2008).

Considering adaptation in terms of capabilities to respond to a stressor and in terms of education allows for the identification of material adaptation, individual and collective actions, and socio-political modification as valid adaptive strategies. The relational attributes of local actors, their degree of knowledge, and social implications are central to adaptive capacity, which enables responses not only to the unforeseen shocks related to climate change, but also to the corollary incertitude of economic, social, and political change (Biconne 2013b). In this framework, the array of adaptation options is very large, ranging from purely technological measures to managerial adaptation and policy reforms (Falkenmark et al. 2007). According to Ngigi (2009), one of the most important features of an adaptation strategy is that it should reflect the needs and aspirations of the society or community to which it is meant to bring an advantage. Thus, the most effective mechanisms are flexible and the adaptation efforts would be coordinated across sectors and between different agents, which is a great challenge in practice.

Therefore, in many cases adaptation activities are local - district, regional or supra-regional - issues rather than international. Since communities show different vulnerabilities and adaptive capabilities, they tend to react differently, thereby showing different adaptation needs. According to Paavola and Adger (2006), successful adaptation at community level will depend on:

- Establishment of appropriate social institutions and arrangements that discourage marginalization of vulnerable populations and enhance collective/participatory decision-making process;

- Diversification of income sources and livelihood systems reducing vulnerability and risks, especially for the poor people;

- Introduction of collective security arrangements such as farmers' cooperatives and community-based organizations;

- Provision of knowledge, technology, policy, institutional and financial support (e.g. credit facilities) to the vulnerable communities;

- Prioritization of local adaptation measures and provision of feedback to stakeholders. 
These main elements outlined by scholars are going to be used in order to discuss the general strategy and the measures of adaptation deployed by the inter-community organization in Mekhe. In the selected case study, the focus will be mainly on the introduction of new technology for water irrigation and related new hybrid forms of management.

The use of water for agricultural purposes related to the on-going CC is a main challenge in many tropical and sub-tropical regions. More than 70 per cent of people living in African, Caribbean and Pacific (ACP) countries work in the agricultural sector: for them, understanding and responding to CC is not only a theoretical debate, it is an existential issue. Precisely, smallholder farmers are the most vulnerable to $\mathrm{CC}$, and they have no alternative but to adapt their livelihood systems to changing climatic conditions.

\subsection{The Case Study of Mékhé}

Mékhé is a municipality in the region of Thiès, the central-northern area of Senegal's historical groundnut basin. Since the time when Senegal was a colony, this area has always been exploited for the production of monoculture for international trade. In this region of the ancient reign of Cayor such a strategic function was carried on after the Independence under the aegis of the national agricultural strategy until the year 2000, when the State marked a turning point by privatizing the groundnut production chain. Such a policy of privatization pushed local farmers to adopt new strategies and engage in growing alternative crops such as manioc, orchards and breeding.

According to the oral tradition, in ancient times the area was full of forests, rich in animal species and had high soil fertility, which eased the development of agricultural and breeding activities, and human settlements. There were not so many villages and the size of agricultural surfaces was not bigger than a hectare. These tiny fields were located at the margins of the concession, the traditional house, paying particular attention to the interchange of times of harvest and periods of fallow (Fall 2009). The farmer system was based on the familial or collective organization.

The development of the settlement of Mékhé was originally linked to its location in one of the main strategic axes in the country, the National Road 2 (RN2). Mékhé is currently the intersection between two main routes connecting the capital city to Saint Louis (the abovementioned RN2) and to Touba (RN3).

As mentioned at the beginning of the chapter, this case study represents a very interesting context in which to investigate because of its localization in the hinterland of the capital city, especially for the on-growing urban corridor between Dakar and Touba (Figure 11.2). This new link between the two large urban centres (the undisputed primacy of the capital city and the growing role of Touba as a religious and economic centre) is the main cause of relevant spatial transformations in the region. 

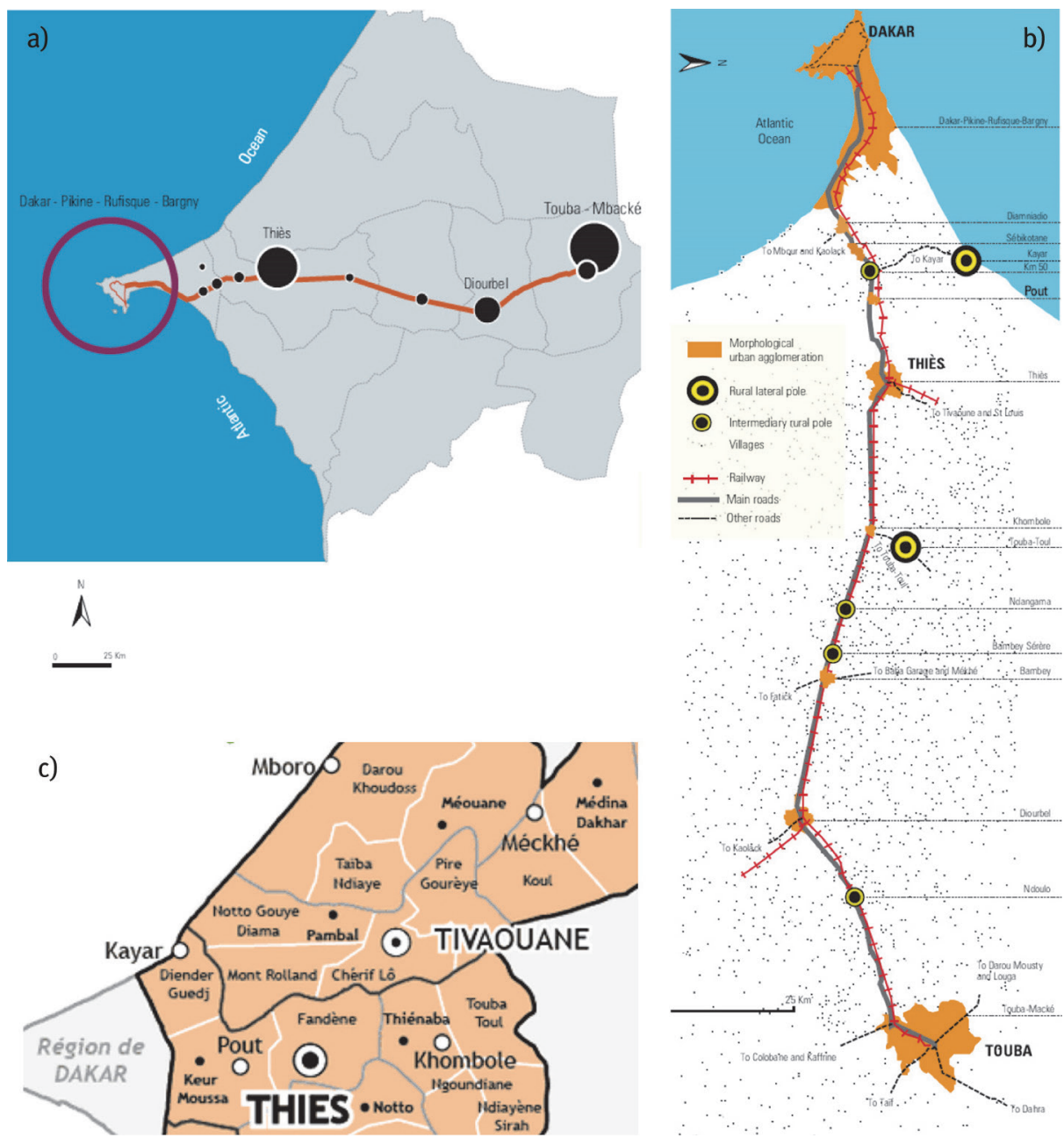

Figure 11.2: The urban corridor of Dakar-Touba in 2002 (a) and 2010 (b) Source: UN-Habitat 2010. Localization of Mékhé (c). Source: www.au-senegal.com.

The 200-km long Dakar-Touba corridor owes its dynamism to the line of towns and cities, which lie along the highway linking these two main urban centres. Thiès, the largest one, stands as a major transition point along the route (UN-Habitat 2010). A number of rural settlements hosting weekly markets lie between the main corridor cities, helping to maintain the commodity flows within the corridor and creating very active lateral links.

Thiès, an area of $6,670 \mathrm{~km}^{2}$ that is $3.4 \%$ of the national territory, is the second most populated region after Dakar. In 2013, it shows an urbanization rate of $49 \%$ and about $14 \%$ of the national urban population (Table 11.1). 
Table 11.1: Data on demographic growth of Thiès region. Source: Conseil Regional de Thies 2007; Ministère du Plan - ANSD 2014.

\begin{tabular}{llll}
\hline Year & $\mathbf{1 9 7 6}$ & $\mathbf{1 9 8 8}$ & $\mathbf{2 0 1 3}$ \\
\hline Total Population & 654,046 & 941,151 & $1,709,112$ \\
Urban Population & 195,906 & 331,549 & 837,331 \\
Rural Population & 458,140 & 609,602 & 871,781 \\
\hline
\end{tabular}

Furthermore, this area was chosen also for the degradation problems due to persistent drought, affecting the agriculture as well as the natural resources. The expansion of Thiès, intense mining activities and overexploitation of the water table have also had a great impact on the neighbourhood. The whole area is thus undergoing deep changes in the organization of land, requiring a redefinition of land use planning (IAO 2003).

Agriculture has historically been the main activity, but now it is undergoing major changes. Up until the 1970s, agriculture flourished thanks to ideal soil, climatic conditions, and market opportunities. Later on, agricultural market outlets become poorer and poorer, due to rainfall decreases, soil erosion, reduction of soil fertility, increased salinity and vegetation degradation, mainly due to deforestation. Nowadays, after the privatization implemented by the national agricultural strategy, the farming patterns in selected areas changed slightly according to the land morphology. However, about $70 \%$ are largely dependent on rainfall and the rest on irrigation, which is fuelled by the shallow water table. Crop production, livestock husbandry and small trading are the main sources of income in this region. The widespread cultivation is rain fed, breeding is extensive and transhumance is common when food for animals is lacking or mainly during the dry season.

This framework is highly aggravated by climate change, essentially consisting of rainfall regime fluctuations and the rise of temperatures, leading to a continuous degradation of the other natural resources. The study of the precipitation index of the Thiès region reveals the contrast between two periods: a first period from 1930 to 1970 with positive rainfall indices in most years, and a second period from 1971 to 2012 with negative rainfall indices for almost all years (ANACIM), (Figure 11.3).

From the point of view of water infrastructure, the region has 75 boreholes realized by the State, with a production capacity of $18,720 \mathrm{~m}^{3}$.

Despite this important hydraulic equipment, the demand for drinking water for human, livestock and agricultural use, estimated at $47,473 \mathrm{~m}^{3} /$ day, is covered at $39 \%$ only.

In rural areas, water consumption comes mainly from boreholes and wells. Wells in particular, which were the main sources of water supply in the villages, are no longer functional due to the lowering of the water table. Therefore, the majority 


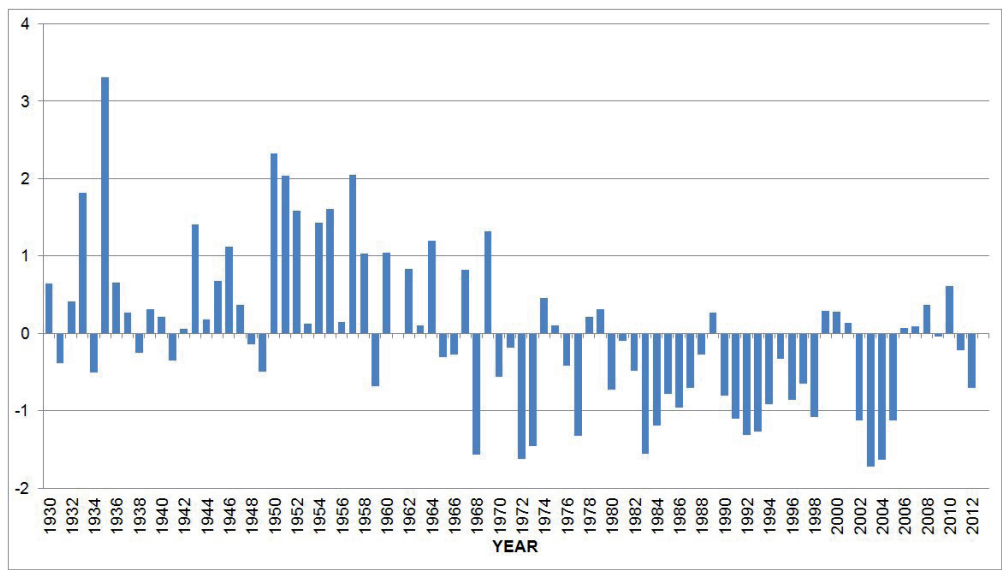

Figure 11.3: Rainfall index of climatological station of Thiès (1930-2012). Source: ANACIM-Senegal National Meteorology Agency.

of villages now rely on drilling for drinking water sold at 250 FCFA per $\mathrm{m}^{3}$, which does not favour the agricultural activities development (Conseil Regional de Thies, 2007).

\subsubsection{Methodology}

The chosen methodology has added to the bibliographic survey the analysis of the case study as a research strategy to empirically deepen the issue, as the border between the examined process and the context is not always easy to identify (Yin 2003). A strategy based upon the usage of multiple sources to gather and analyse information was designed in order to identify "who" and "how" the forms of adaptation are taking shape in conditions of water scarcity.

Added to the complexity of the topic considered is the choice of combining different methods in order to integrate the different levels of analysis. By making use of the tools belonging to ethnography, it was considered expedient to make use of the observation from a distance and the semi-structured interviews in the awareness of the benefits coming from the complementarity of the two techniques. Indeed, the noninvolvement of the researcher in the events, which has led us to choose this method of enquiry due to the high-quality information that it allows to collect, does not entail investigating the way things are perceived and learnt by people, which instead has been outlined through interviews. The detached viewpoint of the observer is useful to learn about interactions and behaviours in the way they usually occur, or - better - without the risk of contamination by external actors (Ronzon 2008). Nevertheless, "the limits of the observation in the distance lie in the fact that in order to provide complete findings it needs to be matched with other techniques allowing more partic- 
ipation, allowing to collect additional contextual information and allowing to understand social roles, functions and the meaning given to the ongoing actions" (Ronzon 2008: 21).

Two types of interviews - individual and collective - were performed according to the need to focus attention on the perception, cognitive and / or technical level of the single person or group. The interviews were conducted in French and sometimes in Wolof with the support of local interpreters. About 30 semi-structured interviews were realized and addressed to several people, as the representatives of the villages - Chefs du village, farmers, the UGPM president, the UGPM representative for sustainable development, the UGPM responsible of the Solar platform project, the UGPM facilitator for peasant groups, a hydraulic technician, the KAYER Laboratory members and technicians, and cooperation project representatives.

The questions were calibrated with respect to the interviewee and concerned different issues, such as: the socio-economic characteristics of the territory; water use and agricultural practices, and related difficulties; the organizational structure of UGPM and peasant groups in the villages; the technological and economic components of the new system, the method of decision-making and agricultural fields management and infrastructure; changes, benefices and limitations of the initiative.

The research was carried out from January 2011 to April 2013, in particular the fieldwork was conducted from January to March 2012.

\title{
11.4 Adaptive Capabilities of the Inter-village Organization
}

\begin{abstract}
"When territory, social actors and the relations between social actors in the local systems of power are not taken into account, the resource management cannot do other than floating in a sociological void allowing bewilderments and manipulations. Moreover, the issues of water management depend on understanding the local arrangements of power." (Lavigne Delville 2005: 155)29.
\end{abstract}

The last three decades have featured bottom-up actions aiming to the re-appropriation and exploitation of local resources in Mékhé, especially water and land. The main agent of this transformation is the Union of peasants of Mékhé (Union des Groupements Paysans de Mékhé - UGPM), which is organized in groups of 90 different villages for a total of 5,000 members. It has had a great evolution if we consider that in 1985, when the Union was created, only 5 groups formed it.

The main choice of UGPM is to improve the living conditions of the peasant groups and to strengthen their role in the protection of natural resources, diversification of sources of income, the fight of the rural exodus and the reinforcement of social solidarity.

29 Translation by author. 
The starting point was the awareness of local needs and potentialities to face anthropic and environmental challenges, fundamental elements recognized by some scholars (Chauveau et al. 1999).

The association recently strengthened this ever-growing knowledge on local conditions and on endogenous understanding and practices deployed in the various villages, by systematizing them in documents and maps. For example, the organization created a map that identifies five agro-ecological zones in the area under UGPM influence (UGPM 2009), based on the peculiarities of the main economic activities, of the nature of the soil and vegetation, of the localization of villages and their relation with near-by settlements and their type of production (manioc, cereals, horticulture, sheep-breeding, groundnuts, pearl millet, and niébé).

\subsubsection{Provision of Knowledge and Technology for the Communities}

The state-led policies aiming at privatization and to agribusiness, as well as the impacts of environmental and climatic factors, have pushed rural communities to seek alternative solutions. The network of peasants groups in Mékhé has tried to introduce new systems of water management and farming that would allow for facing the critical environmental and socio-economic conditions.

In this framework, one of the main interventions of UGPM, supported by a decentralized cooperation program, has been in some villages the realization of solar pumping platforms connected to a network of micro irrigation and water for human consumption (Figure 11.4).

The intervention was based on the reactivation of forage $e^{30}$ in order to build a micro-irrigation system allowing the exploitation of near-by unused horticultural fields (périmètres maraichers). Through giving support to an integrated approach aimed at local development and food security, UGPM has favoured the introduction

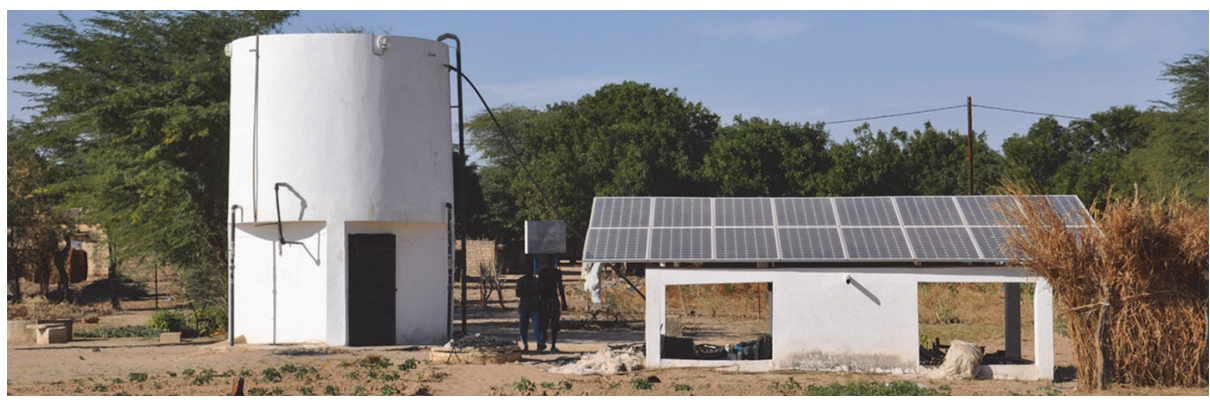

Figure 11.4: The solar platform of village, Ndia (Photo by the author, 2013)

30 Forage is a well drilling that enables reaching deep groundwater, and through a pumping system provides water to the surface. 
of renewable energies as a way to preserve the environment and to enhance the conditions of a local communities lifestyle, also giving support to the process of technological transfer.

The technological transfer of the new system and its related storage and microirrigation is a process entailing information activities and training of some local inhabitants responsible for the intervention, and the progressive assumption of the infrastructures management so as to ease a process of gradual appropriation. The technical sustainability of the new system is mainly guaranteed by the fact that the collective platform goals are set up by existing groups and volunteers, and by KAYER, a local cooperative company created in 2006 by UGPM and funded since 2011 thanks to a microcredit system.

However, through setting up solar energy systems that satisfy domestic and village platforms, the organization has tried to respond to the basic needs identified by the communities as time went by. The problem was finding a way to ease the water access for farming and finding an alternative solution to the usage of expensive generators. This would allow the restoration and the boosting of production for selling, but above all, the survival of the families largely dependent on this activity. The solar platform indeed allows the supply of about 20mc of water per day which is used for irrigation, and no additional costs or forms of payment apply. It is essential to outline that the introduction of technological innovations of solar energy systems is totally in line with the recent national and international guidelines on the replacement of the use of fossil fuels with renewable energy.

Last but not at least, this intervention has represented an opportunity to slow down the process of rural exodus affecting young people of the area: some of them are voluntarily involved in the KAYER laboratory.

\subsubsection{Establishment of Appropriate Social Institution}

Even though the recent Senegalese reform on administrative decentralization has committed the natural resources and land management to local communities for about 20 years, an effective implementation of the decentralized action is still far from being undertaken (Poteete and Ribot 2011). Owing to the lack of institutional answers and measures of environmental and climate change impacts, as well as to the already existing problems, the first reflection is about the role of inter-villages organization. Rooted in the territory and increasingly recognized by the populace, it can represent a useful process of re-appropriation of resources management in a broader vision of endogenous development.

By synthesizing spatial, cultural and social needs of various villages involved, UGPM is a catalyst of the local potentialities and the international engagement, raising alternative forms of response to the current challenges. The organization has revealed the ability to encourage and keep alive the relations within the communities, 
in order to promote social and cultural peculiarities, fostering the exploitation of local resources for empowerment and adaptation process.

Basically there is no conflict between the official and unofficial figures, owing maybe to the perceived distance of the population compared to legal forms of representation and intervention. It amplifies the gap between the channels of planning and territorial government where the institutional authorities seem to be the armed wing of choices distant from and poorly shared by the population. Instead, the capacity of social mobilization makes UGPM a significant experience of community selforganization that over time has been able to convey, coordinate and exploit the social, cultural and productive potentiality.

The growing demand coming from other villages for the construction of solar platforms puts on UGPM an important responsibility for the transmission of approaches and methods linked to this technology, which is undoubtedly favoured by the power and legitimacy granted by the population.

\subsubsection{Collective Decision-making and Socio-territorial Arrangements}

As Venot underlines, small-scale irrigation fits well within the development narrative of participation (Venot 2011). In the selected experience, UGPM was able to undertake the upgrading of the water supply for agricultural purposes thanks to its ability to mobilize endogenous and exogenous resources. The project was proposed and designed during a meeting organised by UGPM as the forerunner of the initiative, to which the members of the peasants' unions in Mékhé had been invited. The first four villages in which to begin the programme were identified on the basis of the adhesions expressed by the spokespeople of the villages during a meeting, and according to the criteria to start the intervention (among them there was the presence of disused forage in the village). This tiny discourse on the initial implementation phase of the programme showed the main features of the decision-making process of the peasants' unions.

As already highlighted, UGPM embodies that role of linkage able to intercept and embrace the main needs of local communities in order to promote an alternative path of development where members and representatives of each community are directly involved and responsible for the initiative. Within the village, this network of relationships can be identified also in the management of the realized hybrid system, where the community choices are mainly discussed and taken inside the meetings to which dwellers and local representatives take part. In these assemblies, a division of the responsibilities and roles related to the entire chain is set up, from water management to land management, from the choice of crops to be plant to the distribution of products and income. For instance, in these assemblies are identified those responsibles for the périmètre maraicher, the contact person for each field, as well as people responsible for the maintenance of forage and hydraulic system. 
The activation of this hybrid water and land management scheme shows an adaptation process - that we could call experimental - of which two main levels of transformation can be highlighted. The first is about the introduction of new horticultural perimeters to collective management (Figure 11.5), a hybrid structure based partly on the need to foster a dynamic access to the available resources, and partly on the rediscovery of exploitations familiales, the traditional structures of farm. Family is indeed recognised as the foundation from which both social and settlement relations most often arise, as well as basis of the production dynamics traditionally centred on the small-scale agricultural activities (UGPM 2009). Family being the core of local activities and initiatives, it is perceived and lived as a valid alterative and - to some extent - as a change-resistant social institution, which is not affected by the dynamics of social fragmentation and environmental challenges.
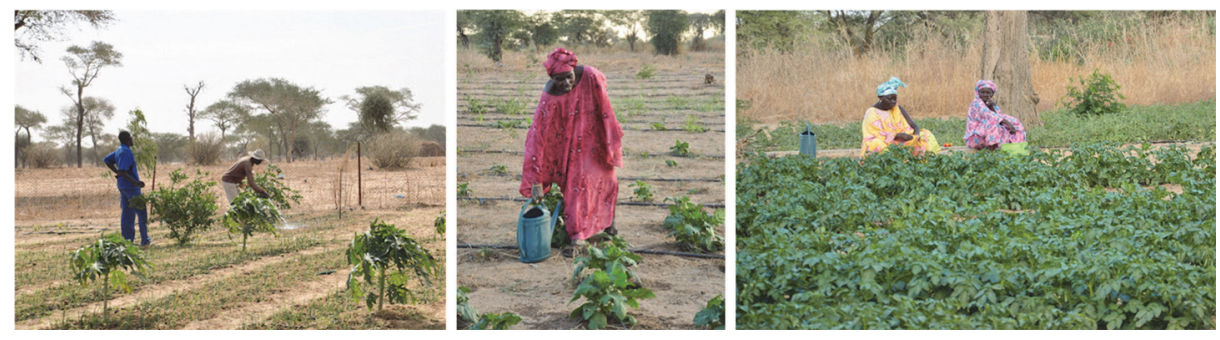

Figure 11.5: Mékhé collective management of the périmètres maraichers (Photos by the author, 2013).

The second issue is related to the changes at a territorial scale. The rehabilitation of community water facilities favoured significant changes in the dynamics of relationships among settlements in the area. First of all, the presence of peasants' groups and their work on the territory (although it may change in the different villages) has meant that every settlement gains a significant weight in the territory.

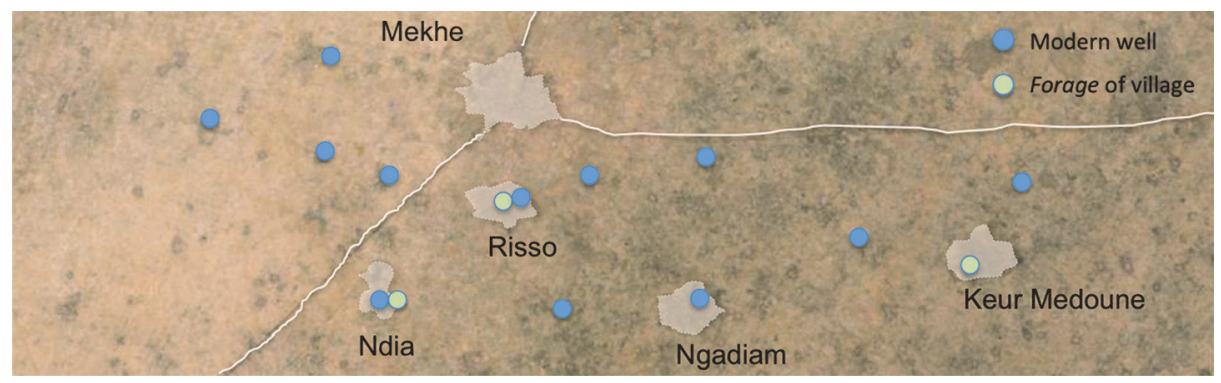

Figure 11.6: Localization of the main points of water (Elaboration of the author, 2013).

Particularly the process of forage, reactivation in some villages (Figure 11.6) has increased the exchanges and inter-village mobility, creating a more complex geography of 
relationships and hierarchies. The new system for the access and use of water raised new functions and related activities that have expanded the range of influence of the village on the surrounding environment involving - more or less directly - the bordering settlements. The increase of horticultural production, the exchange of related products, as well as the dynamics of formal and informal markets, not only attract neighbouring people, but also gradually bring the interest of other professional associations to gravitate to where more opportunities are being created.

\subsection{Conclusions}

The climate change discourse recognises the impact of climate-induced water shortages and stress on the vulnerable and poor communities, due to their lack of resilience.

This chapter aimed to reflect on the "social resources", which are meant to be the abilities of the community to adapt to climate change and to turn this challenge into opportunity.

The case study showed an experience in which the response to cope with water scarcity and the impacts of CC is based on a desire for change in the local community, sustained in the start-up by the technological and economic support of the international cooperation. This path shows the virtues of integration of the rehabilitation and upgrading of water infrastructure and technical components, but indissolubly combining the "rehabilitation" and enhancement of the local socio-economic patterns.

The tangible answer is therefore the increase in water availability and in agricultural production realized in a common framework of organization and management.

From this, a first criterion to be highlighted emerges. The allocation of roles and responsibilities as well as rights of access to available resources, based on socio-cultural peculiarities and on a shared choice of the organization and management forms, is a conditio sine qua non that initiatives or practices cannot provide an effective way of adaptation at the community level.

In this regard, the results of the interviews, used for the reconstruction of the case described, revealed some common elements in the people's opinion. The awareness of an increasingly critical vulnerability and experienced impotence of the individual to cope with it, has given rise to the perception that acting jointly, the network skills and knowledge across the territory may offer a viable alternative strategy.

Compared with the technological aspect, this element provides an answer less tangible but more intense at a procedural level. The considered experience shows a first but crucial step for the shift towards solutions based on the synergy between social and political potential - where "politics" should be understood in the broader sense as the art of governing, and therefore of leading, organizing and administering public goods. 
In this sense, it should be noted that - regardless of the forms through which adaptation can take shape (voluntary rationing schemes, changes in cropping cycles, rainwater harvesting, groundwater mining, technology solutions) - it is undoubtedly the mobilization process, the decisive act at the community level for facing physical scarcity of resources and to the impacts of CC that are most impactful.

In the first part of the chapter, Ohlsson's theory described the method by which shifting the focus from "resource" to "social scarcity" can achieve an improved understanding of why and how certain societies cope with resource scarcity better than others.

But who takes or is able to take the lead in an adaptation process at community level?

An element that becomes so central in this proposal, it is the understanding of the social actors that can collect and deal with individual and collective instances, that take-charge of these, in order to direct them in a shared process of adaptation.

In the case study, the views of interviewed peasant groups emphasized the role of UGPM in helping them to gradually acquire a more detailed awareness on local issues, and to ensure, encourage and keep alive those relations of community, neighbourhood and sometimes symbolism, which keep the social and cultural patterns, by building a consensus more and more entrenched.

On the basis of this reflection, three main features would characterize the "elites", able to gather the potential of the broader social context:

- The awareness and knowledge on territorial specificity, socio-economic issues and on the related criticality/potential of the local resources;

- The quality of legitimacy by various social groups and populations, and therefore the level of authority recognition as guarantor for the entire community (that has a direct impact on the degree of responsibility that it can take);

- The ability to integrate demands and local needs that directly affect the degree of sharing of the community.

In conclusion, it is necessary to take into account that where there is no pre-existing social bias, communities can be supported by referring to their traditions, associations and indigenous systems. Self-management and popular participation are neither immediately nor easily transferable and can be full of pitfalls, however, awareness that the benefits of wide participation instead accrue over time and space is necessary.

\section{References}

Biconne, R. 2013. Discourse and practice on water management in the Southern countries. Planum. The Journal of Urbanism 27 (2): 36-51. ISSN: 1723-0993.

Biconne R. 2013b. Knowledge sharing for adaptation to Climate Change: a case in Malika, Senegal. In Climate change vulnerability in southern african cities. Building knowledge for adaptation, ed. S. Macchi, and M. Tiepolo, 125-140. Springer. doi: 10.1007/978-3-31900672-7. 
Chauveau, J.P., M.C. Cormier-Salem, and E. Mollard. 1999. L'innovation en agriculture. Questions de méthodes et terrains d'observation. Paris: Éditions de l'IRD-Institut de Recherche pour le Développement. Issn: 0998-4658 Isbn: 2-7099-1442-5.

Conseil Regional de Thies. 2007. PRDI-Plan régional de développement intégré de Thies.

Dinar, A., H. Rashid, R. Mendelsohn, and J. Benhin. 2008. Climate change and agriculture in Africa: Impact assessment and adaptation strategies. London: Earthscan.

Eboh, E.C. 2009. Introduction: Debating Policy Options for National Development. Enugu Forum Policy Paper 10. Enugu, Nigeria: AIAE-African Institute for Applied Economics. http://www. aiaenigeria.org/Publications/Policypaper10. pdf.

Falkenmark, M., A. Berntell, A. Jägerskog, J. Lundqvist, M. Matz, and H. Tropp. 2007. On the verge of a new water scarcity: A call for good governance and human ingenuity. SIWI Policy Brief. SIWI.

Fall, A.D. 2009. Etude des impacts écologiques des stratégies économiques des exploitations agricoles familiales rurales dans la région de Mékhé au Sénégal. Mékhé: UGPM.

IPCC-Intergovernmental Panel on Climate Change. 2001. Third Assessment Report of the Intergovernmental Panel on Climate Change. Parts 1, 2 and 3, Synthesis Report and Policy Makers Summaries. Cambridge, UK: Cambridge University Press.

IPCC. 2007. Impact, adaptation and vulnerability contribution of working group I of the IPCC to the third assessment report of IPCC. London: Cambridge University Press.

IAO-Istituto Agronomico per l'Oltremare, Ministero degli Affari Esteri. 2003. Land evaluation in the Province of Thies, Senegal. Professional master "Geomatic and Natural Resources Evaluation".

Jeffrey, P., and M. Gearey. 2006. Integrated water resources management: lost on the road from ambition to realisation? Water Science \& Technology 53 (1): 1-8.

Lavigne Delville, P. 2005. Conditions pour une gestion décentralisée des ressources naturelles. In L'État et la gestion locale durable des forêts en Afrique francophone et à Madagascar, ed. A. Bertrand and P. Montagne. Cirad.

Ministère du Plan, ANSD-Agence Nationale de la Statistique et de la Démographie. 2014. Recensement Général de la Population et de l'Habitat, de l'Agriculture et de l'Elevage (RGPHAE). Rapport Mars 2014.

Ngigi, S.N. 2009. Climate change adaptation strategies: Water resources management options for smallholder farming systems in Sub-Saharan Africa. New York: The MDG Centre for East and Southern Africa, The Earth Institute at Columbia University.

Ohlsson, L., and A. Turton. 1999. Water scarcity and social stability: towards a deeper understanding of key concepts needed to manage water scarcity in developing countries. Occasional paper. London: SOAS-KCL Water Issues Group, University of London.

Paavola, J., T.W. Adger. 2006. Analysis of fair adaptation to climate change. Ecological Economics 56: 594-609.

Parry, J., A. Hammill, and J. Drexhage. 2005. Climate change and adaptation. Manitoba, Canada. http://www.iisd.org/.

Pereira, L.S. 2005. Water and agriculture: Facing water scarcity and environmental challenges. Agricultural Engineering International- The CIGR Journal of Scientific Research and Development 7.

Poteete, A.R., J.C. Ribot. 2011. Repertoires of domination: Decentralization as process in Botswana and Senegal. World Development 39 (3): 439-449. doi:10.1016/j.worlddev.2010.09.013.

Ronzon, F. 2008. Sul campo. Breve guida pratica alla ricerca etnografica. Roma: Meltemi editore.

UGPM-Union des Groupements Paysans de Mékhé. 2009. Pour un développement "social" de la région de Meckhé. Document d'orientation stratégique de l'UGPM.

UNDP-United Nations Development Programme. 2006. Human Development Report “Beyond Scarcity: Power, Poverty and the Global Water Crisis". New York: UNDP-Human Development Report Office. 
UN-Habitat. 2010. The state of African cities 2010, Governance, inequality and urban land markets. Nairobi

UN-Water. 2006. Coping with water scarcity. A strategic issue and priority for system-wide action. UN-Water thematic initiatives.

UN-Water, 2012. World water development report 4. World water assessment programme.

Venot, J.P. 2011. What commons? Rethinking participation in the sub-saharan african water sector. 13th Biennial Conference of the International association for the study of the commons, Hyderabad-India, Jan. 10-14, 2011.

Yin, R.K. 2003. Case study research: design and methods. SAGE Publications.

WBGU-German Advisory Council on Global Change. 1998. World in transition: Ways towards sustainable management of freshwater resources. Report 1997. Berlin, Heidelberg, New York: Springer.

Ziervogel, G., A. Catwright, A. Taas, J. Adejuwon, F. Zermoglio, M. Shale, and B. Smith. 2008. Climate change and adaptation in african agriculture. Research report for Rockefeller foundation prepared by the Stockholm Environment Institute. Stockholm. 